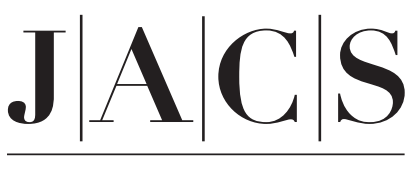

A R T I C L E S

Published on Web 04/10/2003

\title{
Ruthenium(II) Dendrimers Containing Carbazole-Based Chromophores as Branches
}

\author{
Nathan D. McClenaghan, ${ }^{\dagger}$ Rosalba Passalacqua, ${ }^{\dagger}$ Frédérique Loiseau, ${ }^{\dagger}$ \\ Sebastiano Campagna, ${ }^{*}, \dagger$ Bert Verheyde, ${ }^{\ddagger}$ Ahmed Hameurlaine, ${ }^{\ddagger}$ and \\ Wim Dehaen*,

\begin{abstract}
Dipartimento di Chimica Inorganica, Chimica Analitica, e Chimica Fisica, Università di
Leuven, Celestijnenlaan 200F-3001 Heverlee, Leuven, Belgium
\end{abstract} \\ Messina, via Sperone 31, I-98166, Messina, Italy and Department of Chemistry, University of
}

Received November 22, 2002; E-mail: photochem@chem.unime.it; wim.dehaen@chem.kuleuven.ac.be

\begin{abstract}
Three new luminescent and redox-active $\mathrm{Ru}(\mathrm{II})$ complexes containing novel dendritic polypyridine ligands have been synthesized, and their absorption spectra, luminescence properties (both at room temperature in fluid solution and at $77 \mathrm{~K}$ in rigid matrix), and redox behavior have been investigated. The dendritic ligands are made of 1,10-phenanthroline coordinating subunits and of carbazole groups as branching sites. The first and second generation species of this novel class of dendritic ligands (L1 and L2, respectively; see Figure 1 for their structural formulas) have been prepared and employed. The metal dendrimers investigated are $\left[R u(b p y)_{2}(\mathrm{~L} 1)\right]^{2+}\left(\mathbf{1} ;\right.$ bpy $=2,2^{\prime}$-bipyridine $),\left[R u(b p y)_{2}(\mathrm{~L} 2)\right]^{2+}(2)$, and $\left[R u(L 1)_{3}\right]^{2+}$ (3; see Figure 2). For the sake of completeness and comparison purposes, also the absorption spectra, redox behavior, and luminescence properties of $\mathbf{L} 1$ and $\mathbf{L} 2$ have been studied, together with the properties of 3,6-di(tert-butyl)carbazole (L0) and $\left[\mathrm{Ru}(\mathrm{bpy})_{2}(\text { phen })\right]^{2+}(\mathbf{4}$, phen $=1,10$-phenanthroline). The absorption spectra of the free dendritic ligands show features which can be assigned to the various subunits (i.e., carbazole and phenanthroline groups) and additional bands at lower energies (at $\lambda>300 \mathrm{~nm}$ ) which are assigned to carbazole-to-phenanthroline charge-transfer (CT) transitions. These latter bands are significantly red-shifted upon acid and/or zinc acetate addition. Both L1 and L2 exhibit relatively intense luminescence at room temperature in fluid solution (lifetimes in the nanosecond time scale, quantum yields of the order of $10^{-2}-10^{-1}$ ) and at $77 \mathrm{~K}$ in rigid matrix (lifetimes in the millisecond time scale). Such a luminescence is assigned to CT states at room temperature and to phenanthroline-centered $\pi-\pi^{*}$ triplet levels at $77 \mathrm{~K}$. The room-temperature luminescence of L1 and L2 is totally quenched by acid or zinc acetate. The metal dendrimers exhibit the typical absorption and luminescence properties of $\mathrm{Ru}(\mathrm{II})$ polypyridine complexes. In particular, metal-to-ligand charge-transfer (MLCT) bands dominate the visible absorption spectra, and formally triplet MLCT levels govern the excited-state properties. Excitation spectroscopy evidences that all the light absorbed by the dendritic branches is transferred with unitary efficiency to the luminescent MLCT states in 1-3, showing that the new metal dendrimers can be regarded as efficient light-harvesting antenna systems. All the free ligands and metal dendrimers exhibit a rich redox behavior (except L2 and 3, whose redox behavior was not investigated because of solubility reasons), with clearly attributable reversible carbazole- and metal-centered oxidation and polypyridine-centered reduction processes. The electronic interaction between the carbazole redox-active sites of the dendritic ligands is affected by $\mathrm{Ru}(\mathrm{II})$ coordination.
\end{abstract}

\section{Introduction}

Luminescent and redox-active multichromophoric species of designed architecture are at the center of a large interest from many points of view: for example, they can be used to study photoinduced charge-separation processes and energy migration patterns within the arrays, with the final aim of designing efficient supramolecular systems for energy conversion purposes and/or light information devices. ${ }^{1}$

Among the various multichromophoric architectures, luminescent and redox-active dendrimers, and particularly metalcontaining dendrimers, are extensively investigated. ${ }^{2-5}$ Ex-

\footnotetext{
† Università di Messina.

University of Leuven.
}

amples include rigid polynuclear species, with up to 22 metal ions, ${ }^{3 a, 4}$ and species in which a single metal subunit plays the role of the dendrimer core, with organic repeating subunits acting as branches. ${ }^{3 \mathrm{c}-\mathrm{f}}$ These latter species have also been investigated as modified environments for bimolecular quench-

(1) (a) Balzani, V.; Scandola, F. Supramolecular Photochemistry; Horwood Chichester, U.K., 1991. (b) Sauvage, J.-P.; Collin, J.-P.; Chambron, J.-C.; Guillerez, S.; Coudret, C.; Balzani, V.; Barigelletti, F.; De Cola, L. Flamigni, L. Chem. Rev. 1994, 94, 993. (c) Balzani, V.; Juris, A.; Venturi, M.; Campagna, S.; Serroni, S. Chem. Rev 1996, 96, 759. (d) Bignozzi, C. A.; Schoonover, J. R.; Scandola, F. Progr. Inorg. Chem. 1997, 44, 1. (e) De Cola, L.; Belser, P. Coord. Chem. Rev. 1998, 177, 301. (f) Blanco, M.-J.; Jiménez, M. C.; Chambron, J.-C.; Heitz, V.; Linke, M.; Sauvage, J.-P. Chem. Soc. Rev. 1999, 28, 293. (g) Barigelletti, F.; Flamigni, L. Chem. Soc. Rev. 2000, 29, 1.

(2) Newkome, G. R.; Moorefield, C.; Vögtle, F. Dendrimers and Dendrons; Wiley-VCH: Weinheim, Germany, 2001 and references therein. 


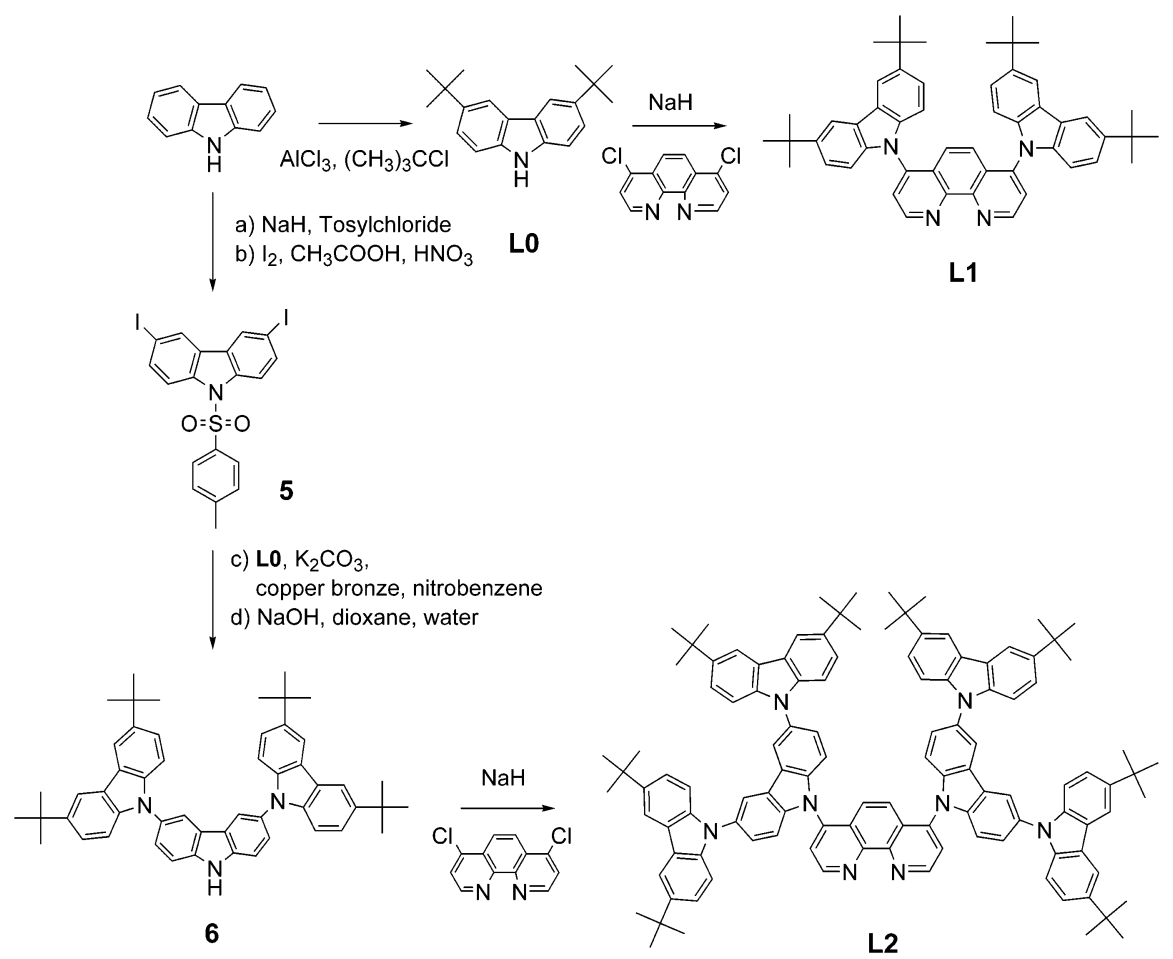

Figure 1. Schematic synthetic procedures for the preparation of the dendritic ligands $\mathbf{L} 1$ and $\mathbf{L 2}$.

ing reactions involving the core chromophore ${ }^{3 \mathrm{c}, \mathrm{d}}$ and as lightemitting diodes. ${ }^{3 e}$ Recently, organic chromophores have been appended at the periphery of metal dendrimers to generate novel light-harvesting antenna systems. ${ }^{5}$

Here, we report on the synthesis, absorption spectra, redox behavior, and photophysical properties of novel metal dendrimers in which the branching subunits are made of carbazole chromophores. The dendritic ligands are the first (L1) and second (L2) generation dendrons having a 1,10-phenanthroline chelating site and two or six additional carbazole chromophores, respectively (see Figure 1). Their absorption spectra, redox behavior, and photophysical properties have also been studied. The new metal dendrimers investigated are $\left[\mathrm{Ru}(\mathrm{bpy})_{2}(\mathrm{~L} 1)\right]^{2+}$ $\left(\mathbf{1}\right.$; bpy $=2,2^{\prime}$-bipyridine $),\left[\mathrm{Ru}(\mathrm{bpy})_{2}(\mathrm{~L} 2)\right]^{2+}(\mathbf{2})$, and $[\mathrm{Ru}-$ $\left.(\mathrm{L} 1)_{3}\right]^{2+}(\mathbf{3})$. For comparison purposes, also the absorption

(3) (a) Balzani, V.; Campagna, S.; Denti, G.; Juris, A.; Serroni, S.; Venturi, M. Acc. Chem. Res. 1998, 31, 26. (b) Constable, E. C. Chem. Commun. 1997, 1073. (c) Issberner, J.; Vögtle, F.; De Cola, L.; Balzani, V. Chem.Eur. J. 1997, 3, 706. (d) Vögtle, F.; Pleovets, M.; Nieger, M.; Azzellini, G. C.; Credi, A.; De Cola, L.; Marchis, V.; Venturi, M.; Balzani, V. J. Am. Chem. Soc. 1999, 121, 6290. (e) Balzani, V.; Ceroni, P.; Juris, A.; Venturi, M.; Campagna, S.; Puntoriero, F.; Serroni, S. Coord. Chem. Rev. 2001, 219-221, 545 and references therein. (f) Lo, S.-C.; Male, N. A. H.; Markham, J. P. J.; Magennis, S. W.; Burn, P. L.; Salata, O. V.; Samuel, I D. W. Adv. Mater. 2002, 14, 975. Complementary information on purely organic photoactive and redox-active dendrimers can be found in many reviews and papers: a list of recent ones is as follows: (g) Yang, S. I.; Seth, J.; Balasubramanian, T.; Kim, D.; Lindsey, J. S.; Holten, D.; Bocian, D. F. J. Am. Chem. Soc. 1999, 121, 4008. (h) Nielsen, M. B.; Lomholt, C.; Becher, J. Chem. Soc. Rev. 2000, 29, 153. (i) Adronov, A.; Fréchet, J. M. J. Chem. Commun. 2000, 1701. (j) Lor, M.; Thielemans, J.; Viaene, L.; Cotlet, M.; Hofkens, J.; Weil, T.; Hampel, C.; Müllen, K.; Verhoeven, J. W.; Van der Auweraer, M.; De Schryver, F. C. J. Am. Chem. Soc. 2002 $124,9918$.

(4) (a) Campagna, S.; Denti, G.; Serroni, S.; Juris, A.; Venturi, M.; Ricevuto, V.; Balzani, V. Chem.-Eur. J. 1995, 1, 211. (b) Serroni, S.; Juris, A.; Venturi, M.; Campagna, S.; Resino Resino, I.; Denti, G.; Credi, A.; Balzani, V. J. Mater. Chem. 1997, 7, 1227.

(5) (a) Zhou, X.; Tyson, D. S.; Castellano, F. N. Angew. Chem., Int. Ed. 2000 39, 4301. (b) Tyson, D. S.; Henbest, K. B.; Bialecki, J.; Castellano, F. N. J. Phys. Chem. A 2001, 105, 8154. (c) McClenaghan, N. D.; Loiseau, F. Puntoriero, F.; Serroni, S.; Campagna, S. Chem. Commun. 2001, 2634. (d) Tyson, D. S.; Luman, C. R.; Castellano, F. N. Inorg. Chem. 2002, 41, 3578 spectra, redox behavior, and luminescence properties of 3,6$\operatorname{di}($ tert-butyl $)$ carbazole $(\mathbf{L O})$ and $\left[\mathrm{Ru}(\text { bpy })_{2}(\text { phen })\right]^{2+}(\mathbf{4}$, phen $=$ 1,10-phenanthroline) have been examined.

While carbazole-containing polymers are well-known, largely due to their photoconductive and photorefractive properties, ${ }^{6}$ carbazole-containing coordination compounds have been much less studied. ${ }^{7}$ To our knowledge, the species reported here are the first examples of metal-containing carbazole-based dendrimers. Moreover, the photoactive ligands $\mathbf{L} \mathbf{1}$ and $\mathbf{L} \mathbf{2}$ are of interest by themselves. Due to the presence of a binding site for cationic guests, which are signaled by a variation in spectroscopic properties, they may have relevance in the area of ionic sensing and molecular logic gates. ${ }^{8}$

\section{Results and Discussion}

Synthesis. Synthesis of the first and second generation carbazole-containing ligands ( $\mathbf{L} \mathbf{1}$ and $\mathbf{L} 2$, respectively) was achieved according to Figure 1. Ligand L1 was prepared in two steps, a Friedel-Crafts alkylation of carbazole ${ }^{9}$ followed by a nucleophilic aromatic substitution of the aryl halide atoms of

(6) (a) Hoegl, H. J. Phys. Chem. 1965, 69, 755. (b) Johnston, G. E. J. Phys Chem. 1974, 78, 1512. (c) Nitzche, L. E.; Chabalowski, C.; Christofferson, R. E. J. Am. Chem. Soc. 1978, 100, 1371. (d) Zhang, Y.; Wada, T.; Wang, L.; Aoyama, T.; Sasabe, H. J. Chem. Soc., Chem. Commun. 1996, 2325. (e) Grigalevicius, S.; Grazulevicius, J. V.; Gaidelis, V.; Jankauskas, V. Polymer 2002, 43, 2603. (f) Schaerlaekens, M.; Hendrickx, E.; Hameurlaine, A.; Dehaen, W.; Persoons, A. Chem. Phys. 2002, 277, 43.

(7) Ribou, A.-C.; Wada, T.; Sasabe, H. Inorg. Chim. Acta 1999, 288, 134.

(8) (a) de Silva, A. P.; Gunaratne, H. Q. N.; Huxley, A. J. M.; McCoy, C. P.; Rademacher, J. T.; Rice, T. E. Chem. Rev. 1997, 97, 1515. (b) Chemosen sors of Ion and Molecule Recognition; Desvergne, J.-P., Czarnik, A. W., Eds.; Kluwer: Dordrecht, The Netherlands, 1997. (c) Armaroli, N.; Eckert, J.-F.; Nierengarten, J.-F. Chem. Commun. 2000, 2105. (d) Credi, A.; Balzani, V.; Langford, S. J.; Stoddart, J. F. J. Am. Chem. Soc. 1997, 119 2679. (e) de Silva, A. P.; McClenaghan, N. D. J. Am. Chem. Soc. 2000, 122, 3965. (f) de Silva, A. P.; McClenaghan, N. D.; McCoy, C. P. in Handbook of Electron Transfer in Chemistry; Balzani, V. (Editor-in-Chief), de Silva, A. P. (Section Editor); Wiley-VCH: Weinheim, Germany, 2001; Vol. 5, p 156 and references therein.

(9) Neugebauer, F. A.; Fisher, H.; Bamberger, S.; Smith, H. O. Chem. Ber 1972, 105, 2686 


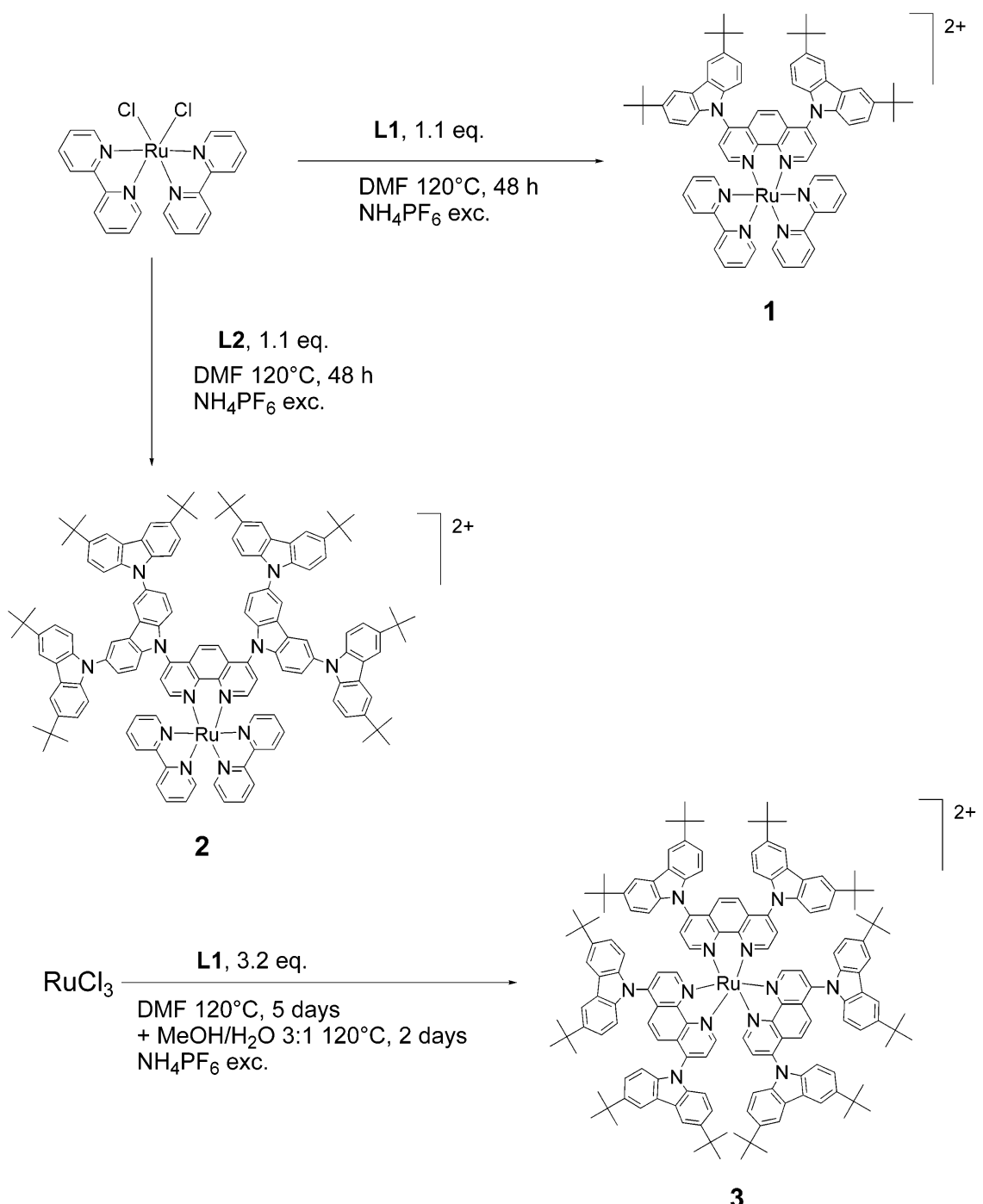

Figure 2. Schematic synthetic procedures for the preparation of the metal dendrimers $\mathbf{1}, \mathbf{2}$, and $\mathbf{3}$.

the phenanthroline precursor. Preparation of ligand $\mathbf{L} 2$ required a multistep process. Tosylation of carbazole and subsequent iodination afforded species $\mathbf{5} \cdot{ }^{10}$ Reaction of $\mathbf{5}$ and $\mathbf{L O}$ followed by deprotection of the carbazole nitrogen gave trimer $\mathbf{6}$. This was reacted with 4,7-dichloro-1,10-phenanthroline to give $\mathbf{L 2}$, using a convergent approach. Metal complexes were prepared using standard procedures, reacting $\mathrm{Ru}(\mathrm{bpy})_{2} \mathrm{Cl}_{2}$ (to give $\mathbf{1}$ and 2 and the model species 4$)^{11}$ or $\mathrm{RuCl}_{3}$ (to give 3$)^{12}$ with the appropriate ligand (L1, L2, or phen; see Figure 2). Attempts to prepare sufficient quantities of $\mathrm{Ru}(\mathrm{L} 2)_{3}{ }^{2+}$ of analytical quality proved unsuccessful, using both conventional synthetic protocols and methods involving microwave irradiation. The metal complexes were isolated as their hexafluorophosphate salts following anion metathesis.

Redox Behavior. The redox data of the studied complexes are gathered in Table 1. Both LO and $\mathbf{4}$ undergo a reversible one-electron oxidation process in acetonitrile solution, at +1.08 $\mathrm{V}$ and $+1.30 \mathrm{~V}$ versus SCE, respectively. The oxidation process of $\mathbf{4}$ is due to a metal-centered process, as reported in the

(10) Tucker, S. H. J. Chem. Soc. 1926, 546.

(11) Sullivan, B. P.; Salomon, D. J.; Meyer, T. J. Inorg. Chem. 1978, 17, 3337

(12) Damrauer, N. H.; Boussie, T. R.; Devenney, M.; McCusker, J. K. J. Am. Chem. Soc. 1997, 119, 8253.
Table 1. Half-Wave Potentials in Argon-Purged Acetonitrile Solution, $298 \mathrm{~K}^{c}$

\begin{tabular}{lll}
\hline compd & \multicolumn{1}{c}{$E_{1 / 2}$ ox (V vs SCE) } & \multicolumn{1}{c}{$E_{1 / 2}$ red (V vs SCE) } \\
\hline $\mathbf{L 0}$ & $1.08[1]$ & \\
$\mathbf{L 1}^{a}$ & $1.49[1], 1.65[1]$ & \\
$\mathbf{1}$ & $1.28[1], 1.50[2]$ & $-1.21[1],-1.48[1],-1.71[1]$ \\
$\mathbf{2}$ & $1.10[2], 1.17[2], 1.40[1], 1.65[2]^{b}$ & $-1.13[1],-1.41[1],-1.80[1]^{b}$ \\
$\mathbf{4}$ & $1.30[1]$ & $-1.40[1],-1.65[1],-1.79[1]^{b}$ \\
\hline
\end{tabular}

${ }^{a}$ In 1,2-dichloroethane. ${ }^{b}$ Irreversible waves. The potential given is taken from differential pulse voltammetry peaks. ${ }^{c}$ The number of exchanged electrons is given in brackets.

literature, ${ }^{13}$ whereas the oxidation of the substituted carbazole is largely centered on the nitrogen atom. Dendrons L1 and L2 are only scarcely soluble in organic solvents, so that we have been able to investigate only the oxidation properties of $\mathbf{L} \mathbf{1}$ in 1,2-dichloroethane: in this solvent, $\mathbf{L} \mathbf{1}$ undergoes two successive one-electron oxidations at +1.49 and $+1.65 \mathrm{~V}$ (Table 1$)$. These processes are assigned to successive one-electron oxidations of the two carbazole subunits. A direct comparison with the oxidation potential of $\mathbf{L O}$ is difficult because of the different solvents used; however a stabilization of the HOMO in $\mathbf{L 1}$ is inferred, as a consequence of the presence of the electron-

(13) Juris, A.; Balzani, V.; Barigelletti, F.; Campagna, S.; Belser, P.; von Zelewsky, A. Coord. Chem. Rev. 1988, 84, 85. 


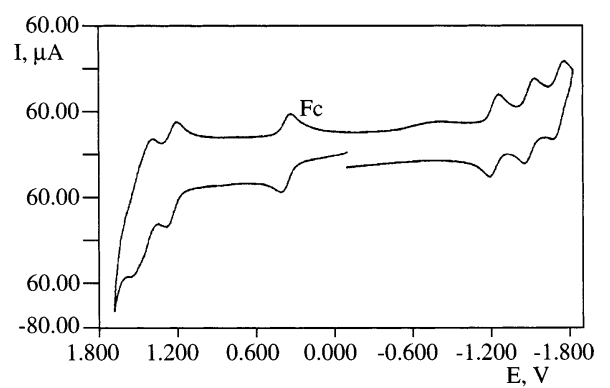

Figure 3. Cyclic voltammogram of $\mathbf{1}$ in acetonitrile. The wave at about $0.4 \mathrm{~V}$ vs SCE is ferrocene, used as reference. Scan rate: $200 \mathrm{mV} / \mathrm{s}$.

withdrawing phenanthroline subunit. The separation of the two oxidation processes indicates that significant electronic interaction between the two carbazole sites takes place in $\mathbf{L} \mathbf{1}$ under these experimental conditions.

The heteroleptic dendritic species $\mathbf{1}$ and $\mathbf{2}$ exhibit several reversible redox processes (Table 1, Figure 3). On oxidation, 1 undergoes a one-electron oxidation at $+1.28 \mathrm{~V}$ followed by a process which involves the exchange of two electrons at +1.50 $\mathrm{V}$. By comparison of the data of $\mathbf{1}$ with those of $\mathbf{4}$ and $\mathbf{L} \mathbf{1}$, the first process is assigned to the metal core oxidation and the successive, bielectronic process is assigned to the simultaneous oxidation of the two carbazole moieties. Interestingly, it appears that metal coordination reduces the electronic interaction between the carbazole subunits of $\mathbf{L} \mathbf{1}$, so that their oxidation takes place at the same potential, on the contrary to what happens for the free, uncoordinated dendron. The reason for such a different behavior is not straightforward: we propose that a possible explaination lies in the modification of the phenanthroline orbitals energy upon metal coordination. Indeed, metal coordination induces a stabilization of the phenanthrolinecentered orbitals, and this can have an important effect on the carbazole-carbazole interactions. ${ }^{14}$

Compound 2, containing the second generation dendron $\mathbf{L 2}$, exhibits a quite rich oxidation behavior: it undergoes four oxidation processes, all of them bielectronic in nature except the third one, which involves only one electron (Table 1). Also in this case, comparison with the redox properties of the other species in Table 1 is very useful to assign the various processes to specific subunits. The first two processes take place at significantly less positive potentials than those of $\mathbf{1}$, so that metal core and carbazole subunits directly connected to the phenanthroline coordination site can be excluded. The potential of the first process is close to that of L0: this suggests that first oxidation can be assigned to simultaneous one-electron oxidation of two peripheral carbazole subunits, one for each branch of the dendron. The second process is assigned to simultaneous one-electron oxidation of the remaining two peripheral carbazoles. Mutual interaction between the external carbazoles of a single branch is not negligible in $\mathbf{2}$, as expected because these subunits are not directly connected to the coordinated phenanthroline site and therefore in some way similar to the carbazoles subunits of the uncoordinated $\mathbf{L} \mathbf{1}$ dendron. Successive oxidation is monoelectronic and can be assigned to metal core oxidation,

(14) The interaction between the carbazole moieties of $\mathbf{L} \mathbf{1}$ can occur via the phenanthroline $\mathrm{HOMO}(\mathrm{s})$, according to a superexchange hole-transfer mechanism, and depends on the energy gap between carbazole-centered and phenanthroline-centered HOMOs (a larger interaction is obtained for a smaller energy gap). This energy gap increases upon phenanthroline metal coordination, leading to a reduced carbazole-carbazole interaction. displaced toward more positive potentials with respect to the corresponding process of $\mathbf{1}$ as a consequence of the occurrence of former oxidation processes in $\mathbf{2}$. Finally, the fourth process is assigned to simultaneous one-electron oxidation of the (weakly interacting) carbazole subunits which are directly connected to the phenanthroline. The reason for the weak interaction between these latter subunits is the same as that discussed for complex $\mathbf{1}$. It could be noted that this latter process is irreversible: tentatively we attribute the irreversibility to accumulation of positive charges on the $\mathbf{L} \mathbf{2}$ ligand in $\mathbf{2}$ upon multiple oxidation processes, which could cause some decomposition.

On reduction, neither $\mathbf{L} \mathbf{0}$ or $\mathbf{L} \mathbf{1}$ exhibit processes within the studied potential window $(+2.00 /-2.00 \mathrm{~V}$ vs SCE). The three heteroleptic metal complexes $\mathbf{1}, \mathbf{2}$, and $\mathbf{4}$ exhibit three monoelectronic reversible processes (Table 1), in line with the reported behavior of $\mathrm{Ru}(\mathrm{II})$ polypyridine complexes, which can be assigned to the three polypyridine ligands (bpy or phen-like) constituting the metal core.

The redox properties of the homoleptic compound $\mathbf{3}$ could not be investigated with confidence for solubility reasons.

Absorption Spectra. A. Free Dendritic Ligands. The absorption spectra of $\mathbf{L} \mathbf{1}$ and $\mathbf{L 2}$ are dominated by strong absorption bands in the $220-300 \mathrm{~nm}$ region $\left(\epsilon\right.$ in the $10^{4}-10^{5}$ $\mathrm{M}^{-1} \mathrm{~cm}^{-1}$ range) and by moderately strong $\left(\epsilon\right.$ in the $10^{3}-10^{4}$ $\mathrm{M}^{-1} \mathrm{~cm}^{-1}$ range) absorption in the $300-400 \mathrm{~nm}$ region (Table 2, Figure 4). The band at about $230 \mathrm{~nm}$, already present in $\mathbf{L O}$, derives from carbazole-centered transitions, whereas the band peaking at about $260 \mathrm{~nm}$ is mainly due to $\pi-\pi^{*}$ transitions centered in the phenanthroline subunit, ${ }^{13}$ although contributions from carbazole-centered transitions are not negligible. As indicated by the absorption spectrum of LO (Figure 4), only very weak absorption bands, obviously due to carbazole-centered transitions, are present for this species at wavelengths longer than $300 \mathrm{~nm}$. While these transitions can also contribute to the moderately strong absorption of $\mathbf{L} \mathbf{1}$ and $\mathbf{L} \mathbf{2}$ at $\lambda>300 \mathrm{~nm}$, we propose that significant contributions in this range for the dendritic ligands are due to carbazole-to-phenanthroline chargetransfer transitions.

This hypothesis is further supported by the changes in the electronic absorption spectra of $\mathbf{L} \mathbf{1}$ and $\mathbf{L} \mathbf{2}$ upon acid addition. Indeed, the presence of acid makes in evidence relatively intense bands in the $350-550 \mathrm{~nm}$ range; for example, a broad absorption band with a maximum at $455 \mathrm{~nm}\left(\epsilon=8000 \mathrm{M}^{-1}\right.$ $\mathrm{cm}^{-1}$ ) appears in the absorption spectrum of $\mathbf{L 1}$, and a broad band which extends to $580 \mathrm{~nm}$ appears in the absorption spectrum of L2 (Figure 5). This can be explained by a red-shift of the carbazole-to-phenanthroline CT transitions, as a consequence of stabilization of the phenanthroline-based acceptor orbitals upon protonation, probably with concomitant enhancements in the oscillator strength of the CT transitions. The bands at $\lambda<300 \mathrm{~nm}$ in the free ligands (not shown in figure), on the contrary, are only weakly affected by protonation, so that for these latter absorption bands the CT contribution is negligible. Despite the contemporary presence of several protonation sites (i.e., four nitrogen atoms in the $\mathbf{L} \mathbf{1}$ and eight in $\mathbf{L 2}$ ), protonation seems to proceed exclusively at the phenanthroline site. Sharp isosbestic points in the absorption spectra, along with the apparent low proton affinity of the parent carbazole (anticipated to be lessened on substitution), lend evidence to this hypothesis. 
Table 2. Absorption and Photophysical Data ${ }^{a}$

\begin{tabular}{|c|c|c|c|c|c|c|}
\hline \multirow[b]{2}{*}{ compd } & \multirow{2}{*}{$\frac{\text { absorption }}{\lambda_{\max }, \mathrm{nm}\left(\epsilon, \mathrm{M}^{-1} \mathrm{~cm}^{-1}\right)}$} & \multicolumn{3}{|c|}{ luminescence, $298 \mathrm{~K}$} & \multicolumn{2}{|c|}{ luminescence, ${ }^{c} 77 \mathrm{~K}$} \\
\hline & & $\lambda_{\max }, \mathrm{nm}$ & $\tau$, ns & $\Phi$ & $\lambda_{\max }, \mathrm{nm}$ & $\tau$ \\
\hline LO & $\begin{array}{l}236 \text { (46 000), } 248 \text { (27 200), } \\
260 \text { (20 800), } 295 \text { (23 100), } \\
327 \text { (3500) }\end{array}$ & 352 & 14 & & $\begin{array}{l}352 \\
405\end{array}$ & $\begin{array}{c}14 \mathrm{~ns} \\
0.9 \mathrm{~ms}\end{array}$ \\
\hline L1 & $\begin{array}{l}232(178000), 260(70300), \\
289(46700), 338(17000), \\
358(7300)\end{array}$ & 486 & 16 & 0.21 & 475 & $2.4 \mathrm{~ms}$ \\
\hline L2 & $\begin{array}{l}235(315000), 266(154700), \\
295(120500), 333(35000), \\
346(35700)\end{array}$ & 530 & 30 & $9.6 \times 10^{-2}$ & 479 & $1.6 \mathrm{~ms}$ \\
\hline 1 & $\begin{array}{l}233(132000), 274(86000), \\
285(91000), 323(17800), \\
335(17600), 478(21000)\end{array}$ & 630 & 760 & $9.2 \times 10^{-2}$ & 600 & $8.2 \mu \mathrm{s}$ \\
\hline 2 & $\begin{array}{l}237(268000), 266 \operatorname{sh}(133000), \\
284(156000), 293(134000), \\
333(30800), 486(18200)\end{array}$ & 650 & 190 & $0.9 \times 10^{-2}$ & 605 & $8.0 \mu \mathrm{s}$ \\
\hline 3 & $\begin{array}{l}233(262000), 271(124000), \\
290(85000), 336(29400), \\
454(31600), 481(30800)\end{array}$ & 630 & 1220 & $7.6 \times 10^{-2}$ & 601 & $5.8 \mu \mathrm{s}$ \\
\hline 4 & $\begin{array}{l}264(55000), 286(63000), \\
448(15700)\end{array}$ & 620 & 640 & $4.3 \times 10^{-2}$ & 580 & $7.0 \mu \mathrm{s}$ \\
\hline
\end{tabular}

${ }^{a}$ In deaerated acetonitrile, unless otherwise stated. Luminescence maxima are corrected for detector response. ${ }^{b}$ For the absorption, the maxima (or shoulders) of the relevant bands are given. ${ }^{c}$ In butyronitrile.

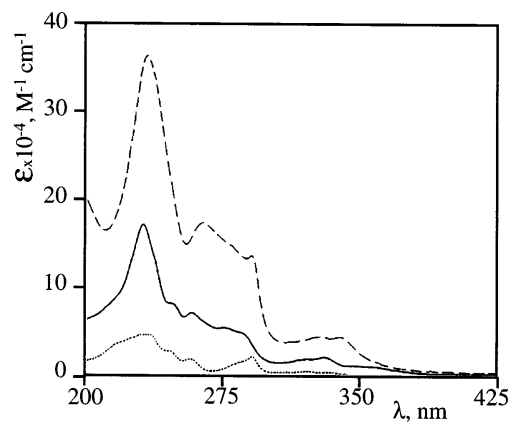

Figure 4. Absorption spectra of L0 (dotted line), L1 (solid line), and L2 (dashed line) in acetonitrile.

The same effect on the absorption spectra of both $\mathbf{L} \mathbf{1}$ and $\mathbf{L} \mathbf{2}$ is also obtained by adding zinc salts; that is, for both species, a broad band which extends significantly into the visible region appears in the presence of zinc(II). Other considerations on acid and zinc salt effects on the spectroscopic properties of $\mathbf{L} \mathbf{1}$ and $\mathbf{L} 2$ are reported in the luminescence properties section (see later).

B. Metal Complexes. The absorption spectra of the metal complexes 1-3 (Table 2, Figure 6) are dominated by intense UV bands ( $\epsilon$ in the range $10^{5}-10^{6} \mathrm{M}^{-1} \mathrm{~cm}^{-1}$ ) and by moderately intense bands in the visible region $(\epsilon$ in the range $\left.10^{4}-10^{5} \mathrm{M}^{-1} \mathrm{~cm}^{-1}\right)$. The UV bands are attributed to spinallowed ligand-centered (LC) transitions, and the visible bands are assigned to spin-allowed metal-to-ligand charge-transfer (MLCT) transitions, according to literature data on $\mathrm{Ru}(\mathrm{II})$ polypyridine complexes. ${ }^{13,15}$ In particular, the band at about 260 $\mathrm{nm}$, which is present in all the complexes, is attributed to LC transitions involving the phenanthroline moiety, and the band at about $285 \mathrm{~nm}$ is the LC transition involving the bpy moieties. The dendritic species $\mathbf{1} \mathbf{- 3}$ exhibit enhanced absorptions around $235 \mathrm{~nm}$ and in the region 300-350 $\mathrm{nm}$ compared to the reference complex 4 . These latter features can therefore be safely assigned to transitions involving the carbazole branches. In

(15) (a) Crosby, G. R. Acc. Chem. Res. 1975, 8, 221. (b) Meyer, T. J. Acc. Chem. Res. 1989, 22, 163. further support of this assignment, such absorption bands increase with the number of carbazole subunits (Figure 6).

The MLCT bands of $\mathbf{1 - 3}$ are broader and shifted toward the red in comparison with that of $\mathbf{4}$ (Figure 6). This is in agreement with the redox data as far as $\mathbf{1}$ and $\mathbf{2}$ are concerned, when the correlation between spectroscopic and electrochemical data is taken into account. ${ }^{13,16}$ Indeed, the lowest-energy MLCT band is related to the $\left(E_{1 / 2} \mathrm{OX}-E_{1 / 2}\right.$ red $)$ value $(\Delta E)$ which is smaller in the complexes containing the dendritic substituents. Compound 3, for which redox data are not available, apparently follows the trend of $\mathbf{1}$ and $\mathbf{2}$. As a consequence, $\mathbf{1 - 3}$ can be regarded as better light-harvesting species compared to the model compound $\mathbf{4}$, since they display enhanced absorption in a region where the absorption of the model compound is poor (the $300-360 \mathrm{~nm}$ region) and also their absorption spectra extend more toward the red.

Luminescence Properties. A. Free Dendritic Ligands. Room Temperature. The luminescence spectra of L1 and L2 in acetonitrile at room temperature are shown in Figure 7, together with the emission spectrum of the model species $\mathbf{L 0}$. The relevant data are collected in Table 2. As one can see, large differences in both energies and shape between the dendritic ligands and $\mathbf{L O}$ are evident. Luminescence of $\mathbf{L 0}$ is assigned to the lowest-lying $\pi-\pi^{*}$ singlet level, on the basis of its energy, lifetime, and structured spectrum (Table 2). On the contrary, the luminescence spectra of $\mathbf{L} \mathbf{1}$ and $\mathbf{L} \mathbf{2}$ are broad and red-shifted. While simple $N$-aryl substituted carbazoles, such as $N$-phenyl carbazole, exhibit red-shifted luminescence compared to their parent luminophore L0, mainly due to the destabilization of the $4 b_{1}$ HOMO orbital, ${ }^{17}$ this effect is small compared to the observed shift for the two dendritic ligands studied here. Therefore, we assign the room-temperature luminescence prop-

(16) Dodsworth, E. S.; Vlcek, A. A.; Lever, A. B. P. Inorg. Chem. 1994, 33, 1045 .

(17) (a) Howell, A. G.; Taylor, A. G.; Phillips, D. Chem. Phys. Lett. 1992, 188, 119. (b) Yu, H.; Mohd Zain, S.; Eigenbrot, I. V.; Phillips, D. Chem. Phys. Lett. 1993, 202, 141. (c) Mohd Zain, S.; Hashim, R.; Taylor, A. G.; Phillips, D. THEOCHEM 1997, 401, 287. (d) Kido, J.; Hongawa, K.; Okuyama, K.; Nagai, K. Appl. Phys. Lett. 1993, 63, 2627. 


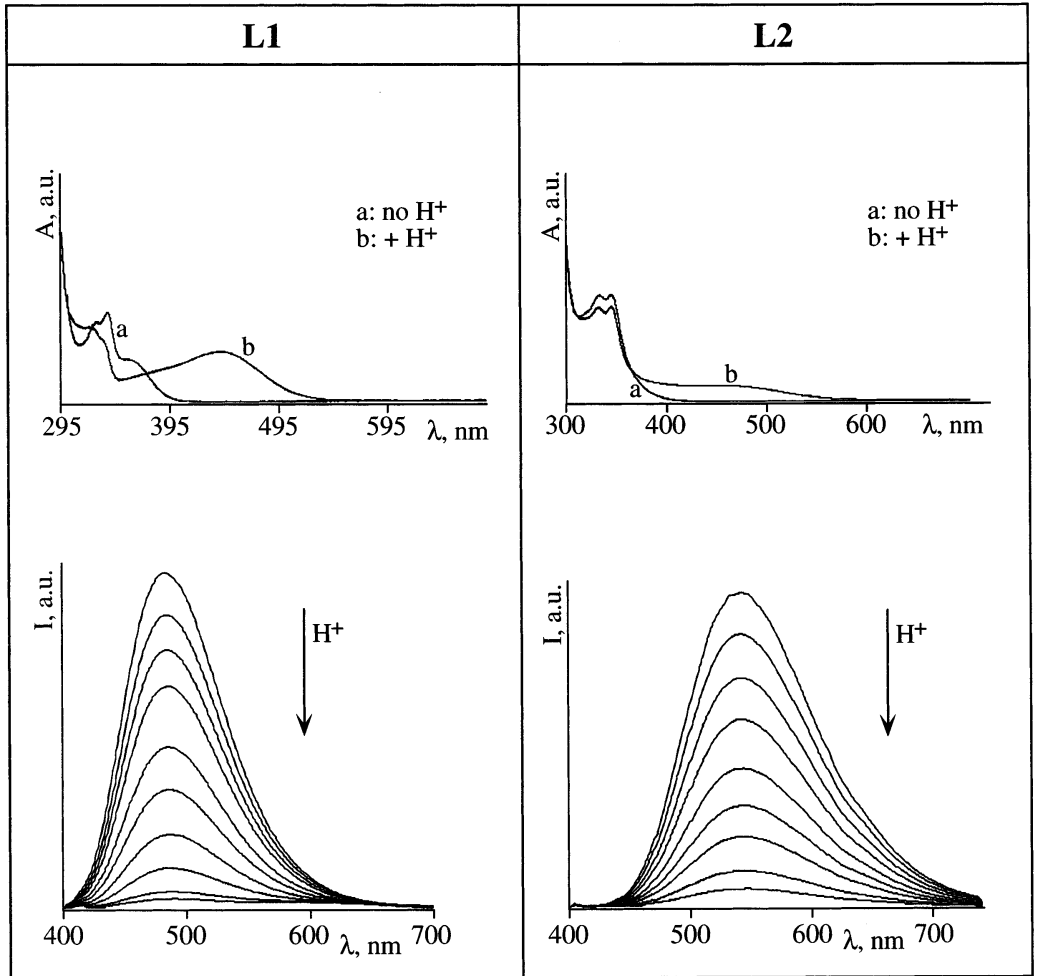

Figure 5. Effect of added acid on the absorption spectra of $\mathbf{L 1}$ (top left) and $\mathbf{L} 2$ (top right) and on the luminescence spectra of $\mathbf{L 1}$ (bottom left) and $\mathbf{L 2}$ (bottom right) at room temperature. Solvent is acetonitrile in all cases.

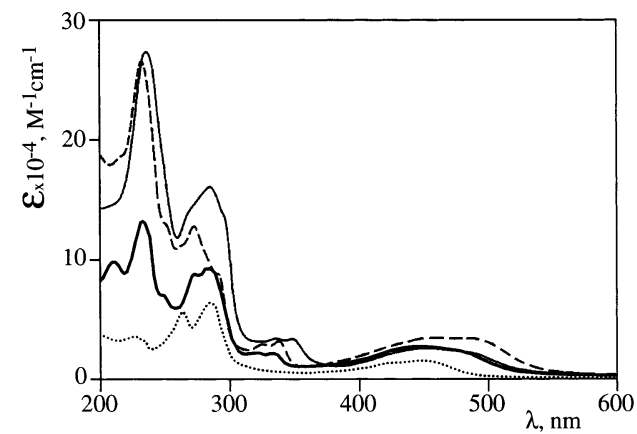

Figure 6. Absorption spectra of $\mathbf{1}$ (thick solid line), $\mathbf{2}$ (thin solid line), $\mathbf{3}$ (dashed line), and $\mathbf{4}$ (dotted line) in acetonitrile.

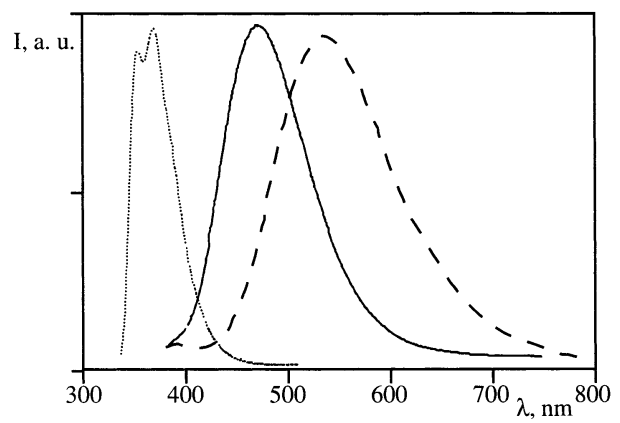

Figure 7. Luminescence spectra of L0 (dotted line), L1 (solid line), and L2 (dashed line) in acetonitrile at room temperature.

erties of $\mathbf{L 1}$ and $\mathbf{L} \mathbf{2}$ to a CT (namely, carbazole-to-phenanthroline) excited state. The larger red-shift of the emission of L2 compared to that of $\mathbf{L 1}$ is in line with this interpretation, if one considers that the CT state should be more stabilized in $\mathbf{L} \mathbf{2}$ than in $\mathbf{L 1}$, as a consequence of possible delocalization of the hole by the outer carbazole-based subunits. Poly-carbazole species

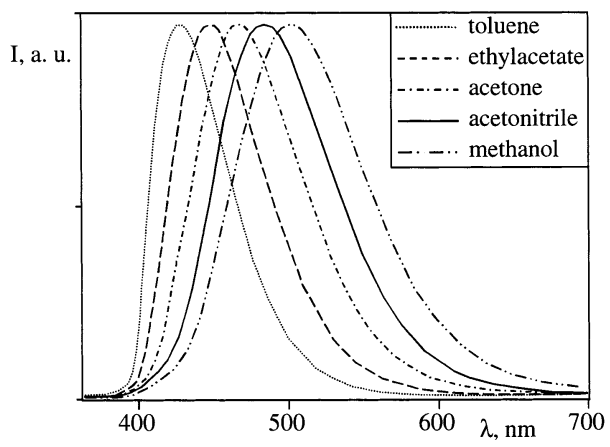

Figure 8. Emission spectra of $\mathbf{L 1}$ in different solvents. Solvents are reported in the inset.

are indeed known to be good hole transporting material with high hole mobility. ${ }^{17 \mathrm{~d}}$ To rationalize the relatively high values of luminescence quantum yields, a significant coupling is expected to exist between adjacent donor and acceptor modules (the carbazole and phenanthroline subunits, respectively) in the excited states. For an enhanced interaction to occur, one may infer that, despite anticipated steric constraints, following excitation some movement toward increased coplanarity between phenanthroline and carbazole subunits takes place during the lifetime of the excited state. A similar conclusion was drawn for anthryl carbazole on the basis of supersonic jet spectroscopic measurements. ${ }^{18}$

The polar nature of the luminescent excited state of $\mathbf{L} \mathbf{1}$ and L2 is further evidenced by the strong dependence of the fluorescence maxima with solvent polarity, shown in Figure 8 (only $\mathbf{L 1}$ is shown for brevity). While absorption spectra show subtle variations in different solvents, emission in high polarity

(18) Phillips, D. J. Photochem. Photobiol., A. 1997, 105, 307. 


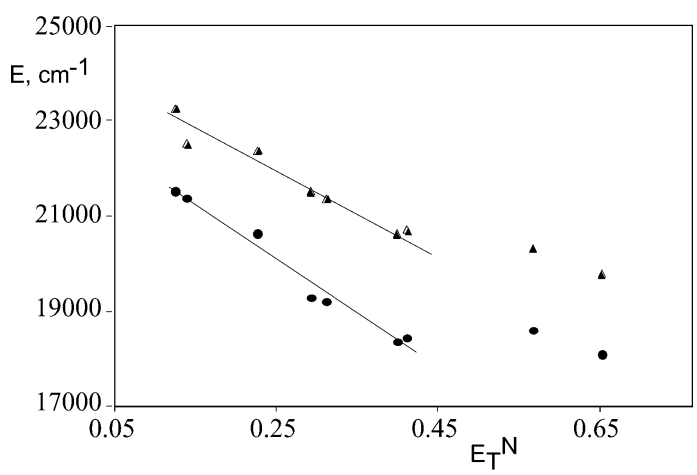

Figure 9. Energy $\left(\mathrm{cm}^{-1}\right)$ of the room-temperature emission maximum of $\mathbf{L 1}$ (triangles) and $\mathbf{L} 2$ (circles) as a function of the $E_{\mathrm{T}}{ }^{\mathrm{N}}$ (normalized values of $E_{\mathrm{T}}(30) \mathrm{scale}^{19}$ ). The solvents employed are (in order of increasing parameter value): toluene, diethyl ether, ethyl acetate, dichloromethane, acetone, dimethyl sulfoxide, acetonitrile, ethanol, methanol. A tabular form of the data is reported as Supporting Information (Table SI-1). Fittings are made excluding the data for the protic solvents.

solvents is significantly red-shifted compared to that in solvents of lower polarity. A rough linear relationship is obtained using the empirical $E_{\mathrm{T}}{ }^{\mathrm{N}}$ parameter (Table SI-1, Figure 9). ${ }^{19}$ Neglecting values obtained in protic solvents (where hydrogen bonding contributes to the observed values, in addition to dipole contributions), we obtain a slightly steeper gradient in the plot of energy of emission maximum as a function of the (solvent polarity) $E_{\mathrm{T}}{ }^{\mathrm{N}}$ parameter for $\mathbf{L} \mathbf{2}$ compared to $\mathbf{L} \mathbf{1}$, suggesting an increased excited-state dipole for $\mathbf{L 2}$ and hence supporting participation of the outer carbazoles in the CT excited state.

Due to their relatively intense luminescence, the dendritic free ligands $\mathbf{L} \mathbf{1}$ and $\mathbf{L} \mathbf{2}$ can also be regarded as luminescent sensors, taking advantage of their free coordination/protonable sites. Indeed, protonation of either $\mathbf{L} \mathbf{1}$ and $\mathbf{L} \mathbf{2}$ similarly results in a red-shifted absorption band and a diminished intensity of luminescence (see Figure 4), without the apparence of other (red-shifted) luminescence bands. This latter result indicates that the carbazole-to-phenanthroline CT levels in the protonated species deactivate quasi-exclusively by radiationless transitions. Comparison of the titration curves obtained from absorption and emission spectra show that $50 \%$ titration occurs at similar respective concentrations of protons in each case, for both species (Supporting Information, Figure SI-1). Rather than attributing this result to an excited-state $\mathrm{p} K_{\mathrm{a}}$ value identical to that of the ground state (which can be dismissed on the basis of the CT character discussed previously), we believe it is most likely due to the diffusion-rate-limited binding process which cannot compete with the short lifetime of the excited states of $\mathbf{L 1}$ and $\mathbf{L 2}$. Similar results are also obtained upon $\mathrm{Zn}^{2+}$ addition to acetonitrile solutions of $\mathbf{L} \mathbf{1}$ and $\mathbf{L 2}$ (Figure 10). The observed emission is greatly diminished $\left(\phi_{\text {free }} / \phi_{\mathrm{zn}}>100\right)$. Reasons for the influence of the zinc salts on the luminescence properties are the same as discussed previously for the protonation case.

It could also be noted that $\mathbf{L} \mathbf{1}$ and $\mathbf{L} \mathbf{2}$ may be of interest in the field of molecular logic gates. ${ }^{8}$ A similar response elicited by zinc and protons affords a two-input photoionic molecular NOR gate, utilizing ionic inputs and a photonic output. With low fluorescence outputs ( 0 ) for input conditions 01,10 , and 11 (the two digits refer to the presence of protons and $\mathrm{Zn}^{2+}$ cations) and a high output (1) for 00, the truth table is demonstrated.

(19) Reichardt, C. Chem. Rev. 1994, 94, 2319-2358 and references therein.
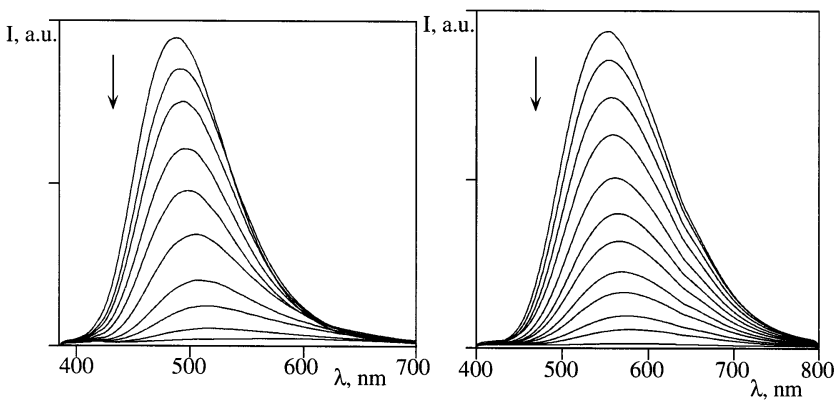

Figure 10. Effect of successive zinc acetate additions on the emission spectra of $\mathbf{L 1}$ (left) and $\mathbf{L 2}$ (right). Excitation wavelength was the isosbestic point.

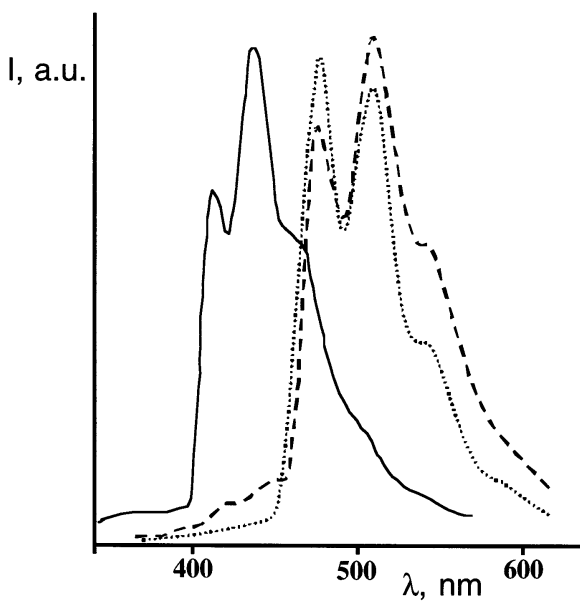

Figure 11. Emission spectra of L0 (solid line), L1 (dashed line), and L2 (dotted line) in butyronitrile matrix at $77 \mathrm{~K}$. For Lo, only the long-lived emission is shown.

B. Free Dendritic Ligands. Low Temperature. The reference carbazole species L0 exhibits two emissions in butyronitrile rigid matrix at $77 \mathrm{~K}$, with the highest-energy maxima at 352 $\mathrm{nm}$ and at $405 \mathrm{~nm}$, respectively. In particular, the highest-energy emission is practically identical to the room-temperature emission, both in energy, shape, and lifetime (Table 2) and is assigned to fluorescence from the lowest-lying $\pi-\pi^{*}$ singlet level. The low-energy emission is long-lived (Table 2) and is therefore assigned to emission from the corresponding triplet state. As far as the dendritic species $\mathbf{L} \mathbf{1}$ and $\mathbf{L} \mathbf{2}$ are concerned (Figure 11, Table 2), only the long-lived emission was obtained. It is interesting to note that such emissions lie at very close energies, despite the emission energy difference found for the room-temperature emissions. A decisive argument for the assignment of the emission of the dendritic species comes from their lifetimes, which are in the millisecond time scale: this time scale suggests in fact a $\pi-\pi^{*}$ triplet origin, most likely phenanthroline-centered, ${ }^{20}$ indicating that deactivation to the CT level is not accessible in this condition, probably because this latter state is destabilized by the frozen environment.

(20) The highest-energy feature of the structured $77 \mathrm{~K}$ emission of protonated phen in alcoholic matrixes is at $485 \mathrm{~nm},{ }^{21}$ and that of the structured $77 \mathrm{~K}$ emission of $\left[\mathrm{Rh}(\mathrm{bhq})_{2}(\mathrm{phen})\right]^{+}$(bhq $=$monoanion of benzo[ $\left.h\right]$ quinoline $)$ in nitrile mixtures is at $486 \mathrm{~nm}$ (lifetime, $4.35 \mathrm{~ms}$ ). ${ }^{22}$ In both cases, emission has been assigned to phenanthroline-centered $\pi-\pi^{*}$ triplet levels. Although the phenanthroline subunits in both the above-mentioned systems are expected to be differently perturbed than those in $\mathbf{L 1}$ and $\mathbf{L 2}$, the similitude in emission energies, shapes, and lifetimes (where available, i.e., in the rhodium species) strongly supports a similar assignment also for the $77 \mathrm{~K}$ emission of $\mathbf{L 1}$ and $\mathbf{L} \mathbf{2}$. 


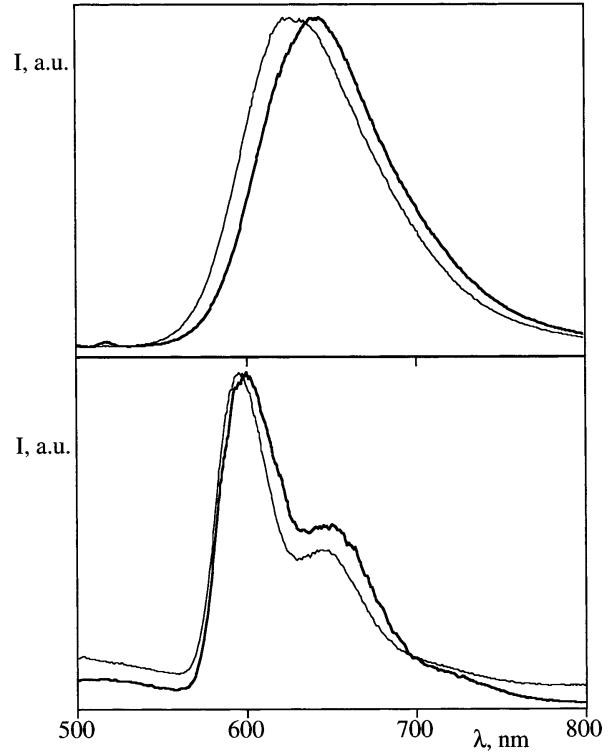

Figure 12. Room temperature (top, acetonitrile fluid solution) and $77 \mathrm{~K}$ (bottom, butyronitrile rigid matrix) emission spectra of $\mathbf{1}$ (thin line) and $\mathbf{2}$ (thick line).

C. Metal Complexes. All the metal complexes studied here exhibit relatively intense luminescence both in acetonitrile fluid solution at room temperature and in butyronitrile rigid matrix at $77 \mathrm{~K}$ (Table 2, Figure 12). Emission energies, lifetimes, spectra, and quantum yields, as well as comparison with literature data, ${ }^{13}$ allow for assignment of the emission to (formally triplet) MLCT states in all the cases. In particular, emissions of $\mathbf{1}$ and $\mathbf{2}$ should originate from a Ru-to-bpy CT state, according to redox data, while of course the emission of 3 comes from a Ru-to-L1 CT state. This difference can be responsible for the different low-temperature luminescence lifetimes of the complexes, which are not in agreement with the energy gap law. ${ }^{13,15,23}$ At room temperature, differences in the excited-state dynamics can also derive from an energy gap between MLCT and metal-centered (MC) levels, ${ }^{13}$ difficult to locate in energy in the various complexes, so that scattering of luminescence lifetimes is not surprising.

An interesting result is obtained from excitation spectroscopy: excitation spectra closely match the corresponding absorption spectra of $\mathbf{1 - 3}$ at least at room temperature (we cannot perform reliable excitation spectroscopy at $77 \mathrm{~K}$ because of technical problems). This indicates that all the light absorbed by the various excited states is transferred with the same efficiency (presumably unitary, since intersystem crossing efficiency within the MLCT manifold in $\mathrm{Ru}(\mathrm{II})$ polypyridine complexes is known to be practically unitary ${ }^{24}$ ) to the luminescent MLCT level(s). This also includes the light absorbed by the photoactive dendritic branches. As a consequence, the new species $\mathbf{1}-\mathbf{3}$ behave as efficient light-harvesting antenna systems.

(21) Hillis, J.; De Armond, M. K. J. Lumin. 1971, 4, 273.

(22) (a) Ohsawa, Y.; Sprouse, S.; King, K. A.; De Armond, M. K.; Hanck, K. W.; Watts, R. J. J. Phys. Chem. 1987, 91, 1041. (b) Maestri, M.; Balzani, V.; Deuschel-Cornioley, C.; von Zelewsky, A. Adv. Photochem. 1992, 17 1 .

(23) (a) Freed, K. F.; Jortner, J. J. Chem. Phys. 1970, 52, 6275. (b) Caspar, J. V.; Meyer, T. J. J. Phys. Chem. 1983, 87, 952.

(24) (a) Bradley, P. C.; Kress, N.; Hornberger, B. A.; Dallinger, R. F.; Woodruff, W. H. J. Am. Chem. Soc. 1989, 103, 7441. (b) Cooley, L. F.; Bergquist, P.; Kelley, D. F. J. Am. Chem. Soc. 1990, 104, 2612. (c) Damrauer, N. H.; Cerullo, G.; Yeh, A.; McClusker, J. K. Science 1997, 275, 54.

\section{Conclusions}

Two novel dendritic ligands, containing phenanthroline coordination sites and carbazole branching subunits, have been prepared, along with three of their $\mathrm{Ru}(\mathrm{II})$ dendritic complexes. The absorption spectra, luminescence properties (at room temperature in fluid solution and at $77 \mathrm{~K}$ in rigid matrix), and redox behavior of the free ligands and of the metal complexes have been studied. The absorption spectra and redox behavior of both free ligands and metal dendrimers are very rich; however, the absorption bands and redox processes can be assigned to specific subunits of the multicomponent systems. All the free dendritic ligands and metal dendrimers exhibit luminescence in all the conditions studied. For the dendritic ligands, room-temperature emission has been assigned to carbazole-to-phenanthroline CT levels and $77 \mathrm{~K}$ emission has been assigned to $\pi-\pi^{*}$ triplet states centered in the phenanthroline subunits. The metal complexes exhibit the usual MLCT emission of $\mathrm{Ru}(\mathrm{II})$ polypyridine complexes; the excited states localized in the dendritic branches efficiently deactivates to the lowest-lying MLCT state(s), so indicating that the new metal dendrimers here investigated can be regarded as efficient lightharvesting antenna systems.

\section{Experimental Section}

I. Equipment and Procedures for the Determination of the Spectroscopic, Photophysical, and Redox Properties. NMR spectra were acquired on commercial instruments (Bruker Avance $300 \mathrm{MHz}$ or Bruker AMX $400 \mathrm{MHz}$ ), and chemical shifts (delta) are reported in parts per million referenced to internal residual solvent protons $\left({ }^{1} \mathrm{H}\right)$ or the carbon signal of deuterated solvents $\left({ }^{13} \mathrm{C}\right)$. Mass spectrometry data were obtained with an HP MS apparatus 5989A (chemical ionization (CI), $\mathrm{CH}_{4}$ ) or a Micromass Quattro II apparatus (electrospray ionization (ESI); solvent mixture, $\mathrm{CH}_{2} \mathrm{Cl}_{2} / \mathrm{MeOH}+\mathrm{NH}_{4} \mathrm{OAc}$ ).

Electronic absorption spectra were recorded on a Kontron Uvikon 860 spectrophotometer. For steady-state luminescence measurements, a Jobin Yvon-Spex Fluoromax 2 spectrofluorimeter was used, equipped with a Hamamatsu R3896 photomultiplier, and the spectra were corrected for photomultiplier response using a program purchased with the fluorimeter. For the luminescence lifetimes, an Edinburgh OB 900 time-correlated single-photon-counting spectrometer was used in the nanosecond and microsecond ranges, whereas a Perkin-Elmer LS-5B spectrometer was used for the lifetimes determination in the millisecond range. As excitation sources, a Hamamatsu PLP 2 laser diode (59 ps pulse width at $408 \mathrm{~nm}$ ) and the nitrogen discharge (pulse width, $2 \mathrm{~ns}$ at $337 \mathrm{~nm}$ ) were employed. Luminescence quantum yields have been calculated by the optically diluted method. ${ }^{25}$ Titrations were carried out using dilute solutions $\left(1 \times 10^{-5} \mathrm{M}\right)$ of ligand in acetonitrile, adding aliquots of relatively concentrated solutions of trifluoroacetic acid (Aldrich) or zinc acetate (Aldrich) in acetonitrile. Volumes added were negligible compared to the volume of the solution.

Electrochemical measurements were carried out in argon-purged acetonitrile or 1,2-dichloroethane at room temperature with a PAR 273 multipurpose equipment interfaced to a PC. The working electrode was a glassy carbon $\left(8 \mathrm{~mm}^{2}\right.$, Amel) electrode. The counter electrode was a Pt wire, and the reference electrode was an SCE separated with a fine glass frit. The concentration of the complexes was about $5 \times 10^{-4} \mathrm{M}$. Tetrabutylammonium hexafluorophosphate was used as supporting electrolyte, and its concentration was $0.05 \mathrm{M}$. Cyclic voltammograms were obtained at scan rates of 20,50,200, and $500 \mathrm{mV} / \mathrm{s}$. For reversible processes, half-wave potentials (vs SCE) were calculated as the average of the cathodic and anodic peaks. The criteria for reversibility were the separation of $60 \mathrm{mV}$ between cathodic and anodic peaks, the close-

(25) Demas, J. N.; Crosby, G. A. J. Phys. Chem. 1971, 75, 991. 
to-unity ratio of the intensities of the cathodic and anodic currents, and the constancy of the peak potential on changing scan rate. The number of exchanged electrons was measured with differential pulse voltammetry (DPV) experiments performed with a scan rate of $20 \mathrm{mV} /$ $\mathrm{s}$, a pulse height of $75 \mathrm{mV}$, and a duration of $40 \mathrm{~ms}$ and by taking advantage of the presence of ferrocene used as the internal reference.

Experimental uncertainties were as follows: absorption maxima, \pm 2 $\mathrm{nm}$; molar absorption coefficients, $10 \%$; emission maxima, $\pm 5 \mathrm{~nm}$; excited-state lifetimes, $10 \%$; luminescence quantum yields, $20 \%$; redox potentials, $\pm 10 \mathrm{mV}$.

II. Synthesis. A. General Notes. All manipulations were performed under a dry nitrogen atmosphere using standard techniques. $\mathrm{RuCl}_{3}$ hydrate was obtained from Aldrich and used as received. THF was distilled over sodium/benzophenone immediately before use. 3,6-Di(tert-butyl)carbazole, ${ }^{9}$ 9-(toluene-4-sulfonyl)carbazole, ${ }^{10}$ 3,6-diiodo-9(toluene-4-sulfonyl)carbazole, ${ }^{10}$ and complexes $\mathrm{Ru}(\mathrm{bpy})_{2} \mathrm{Cl}_{2}{ }^{11}$ and $\mathbf{4}^{12}$ were prepared according to literature procedures.

B. 4,7-Bis(3,6-di-tert-butyl-carbazol-9-yl)-[1,10]phenanthroline (L1). A mixture of 3,6-di(tert-butyl)-9H-carbazole, L0 (280 mg, 1.0 $\mathrm{mmol})$, and $\mathrm{NaH}(38.6 \mathrm{mg}, 1.6 \mathrm{mmol})$ in THF (25 mL) was stirred at $70{ }^{\circ} \mathrm{C}$ for $30 \mathrm{~min} .4,7-$-Dichlorophenanthroline $(100 \mathrm{mg}, 0.4 \mathrm{mmol})$ was added to the reaction mixture, and it was allowed to reflux overnight. THF was evaporated, and the residue was dissolved in dichloromethane. After washing with water, drying over $\mathrm{MgSO}_{4}$ and evaporating the solvent, we purified the crude product by column chromatography on silica gel, eluting with dichloromethane/methanol (20:1, v/v). Evaporating to dryness gave a white solid product $(155 \mathrm{mg}$, yield $=53 \%)$. Mp $>350{ }^{\circ} \mathrm{C} ;{ }^{1} \mathrm{H} \mathrm{NMR}\left(300 \mathrm{MHz}, \mathrm{CDCl}_{3}, \mathrm{ppm}\right) \delta 9.43\left(2 \mathrm{H}, \mathrm{d},{ }^{3} J=4.8\right.$ $\mathrm{Hz}), 8.14\left(4 \mathrm{H}, \mathrm{d},{ }^{4} J=1.8 \mathrm{~Hz}\right), 7.82\left(2 \mathrm{H}, \mathrm{d},{ }^{3} J=4.8 \mathrm{~Hz}\right), 7.45(2 \mathrm{H}$, s), $7.40\left(4 \mathrm{H}, \mathrm{dd},{ }^{3} J=8.8 \mathrm{~Hz},{ }^{4} J=1.8 \mathrm{~Hz}\right), 7.00\left(4 \mathrm{H}, \mathrm{d},{ }^{3} J=8.8\right.$ $\mathrm{Hz}), 1.44(36 \mathrm{H}, \mathrm{s}) ;{ }^{13} \mathrm{C} \mathrm{NMR}\left(400 \mathrm{MHz}, \mathrm{CDCl}_{3}, \mathrm{ppm}\right) \delta 151.3,143.9$, 139.6, 126.4, 124.0, 122.9, 122.4, 116.5, 109.5, 34.8, 31.9; MS(ES) $m / z 826\left(\mathrm{M}+\mathrm{NH}_{4} \mathrm{OAc}+\mathrm{CH}_{3}\right)$.

C. 3,6,3", $6^{\prime \prime}$-Tetrakis-tert-butyl-9' -(toluene-4-sulfonyl)-9' $\boldsymbol{H}$-[9,3'; 6', $\left.^{\prime \prime}\right]$ tercarbazole. A mixture of 3,6-di(tert-butyl)carbazole (1.18 g, $4.25 \mathrm{mmol}$ ), 3,6-diiodo-9-(toluene-4-sulfonyl)carbazole (1.00 g, 1.7 $\mathrm{mmol})$, potassium carbonate $(1.17 \mathrm{~g}, 8.5 \mathrm{mmol})$, and copper bronze $(0.25 \mathrm{~g})$ in nitrobenzene $(7 \mathrm{~mL})$ was heated overnight at $170{ }^{\circ} \mathrm{C}$. After the mixture was cooled to room temperature, chloroform was added and the mixture was filtered. Solvents were removed under reduced pressure, and the residue was purified by chromatography on silica gel with a mixture of hexane/chloroform (7:3 to 5:5, v/v) as eluent. After removal of solvents, the protected trimer product was obtained as a white solid $(1.40 \mathrm{~g}$, yield $=66 \%) . \mathrm{Mp}>300{ }^{\circ} \mathrm{C} ;{ }^{1} \mathrm{H}$ NMR $(300$ $\left.\mathrm{MHz}, \mathrm{CDCl}_{3}, \mathrm{ppm}\right) \delta 8.55\left(2 \mathrm{H}, \mathrm{d},{ }^{3} J=8.7 \mathrm{~Hz}\right), 8.13\left(4 \mathrm{H}, \mathrm{d},{ }^{4} J=\right.$ $1.5 \mathrm{~Hz}), 8.04\left(2 \mathrm{H}, \mathrm{d},{ }^{4} J=2.0 \mathrm{~Hz}\right), 7.90\left(2 \mathrm{H}, \mathrm{d},{ }^{3} J=8.5 \mathrm{~Hz}\right), 7.71$ $\left(2 \mathrm{H}, \mathrm{dd},{ }^{3} J=8.7 \mathrm{~Hz},{ }^{4} J=2.0 \mathrm{~Hz}\right), 7.43\left(4 \mathrm{H}, \mathrm{dd},{ }^{3} J=8.7 \mathrm{~Hz},{ }^{4} J=\right.$ $1.8 \mathrm{~Hz}), 7.28(6 \mathrm{H}, \mathrm{m}), 2.39(3 \mathrm{H}, \mathrm{s}), 1.45(36 \mathrm{H}, \mathrm{s}) ;{ }^{13} \mathrm{C}$ NMR $(300$ $\left.\mathrm{MHz}, \mathrm{CDCl}_{3}, \mathrm{ppm}\right) \delta 145.9,143.4,139.9,137.8,135.4,135.0,130.5$, $127.5,127.2,124.1,123.8,118.9,116.7,109.4,35.2,32.4,22.1$; MS (CI) $m / z 876\left(\mathrm{M}+\mathrm{H}^{+}\right)$.

D. $3,6,3^{\prime \prime}, 6^{\prime \prime}$-Tetrakis-tert-butyl-9' $H-\left[9,3^{\prime} ; 6^{\prime}, 9^{\prime \prime}\right]$ tercarbazole. A mixture of the protected trimer $(0.7 \mathrm{~g}, 0.8 \mathrm{mmol})$ and an excess of sodium hydroxide $(3 \mathrm{~g}$ ) was dissolved in a mixture of dioxane/water $(4: 1, \mathrm{v} / \mathrm{v} ; 12 \mathrm{~mL})$ and refluxed overnight. After extraction with chloroform, the organic layer was washed with dilute hydrochloric acid, dried over $\mathrm{MgSO}_{4}$, and concentrated under reduced pressure. The resulting residue was further purified by column chromatography on silica gel, eluting with a mixture of hexane/ethyl acetate $(9: 1$ to $7: 3$, $\mathrm{v} / \mathrm{v})$. Evaporating to dryness gave the trimer as a white solid product $(0.40 \mathrm{~g}$, yield $=61 \%) . \mathrm{Mp}>300{ }^{\circ} \mathrm{C} ;{ }^{1} \mathrm{H}$ NMR $\left(300 \mathrm{MHz}, \mathrm{CDCl}_{3}\right.$, ppm) $\delta 8.41\left(1 \mathrm{H}\right.$, br. s), $8.15\left(6 \mathrm{H}, \mathrm{d},{ }^{4} J=1.3 \mathrm{~Hz}\right), 7.68\left(2 \mathrm{H}, \mathrm{d},{ }^{3} J\right.$ $=8.4 \mathrm{~Hz}), 7.60\left(2 \mathrm{H}, \mathrm{dd},{ }^{4} J=1.8 \mathrm{~Hz},{ }^{3} J=8.5 \mathrm{~Hz}\right), 7.44\left(4 \mathrm{H}, \mathrm{dd},{ }^{4} J\right.$ $\left.=1.8 \mathrm{~Hz},{ }^{3} \mathrm{~J}=8.5 \mathrm{~Hz}\right), 7.30\left(4 \mathrm{H}, \mathrm{d},{ }^{3} J=8.7 \mathrm{~Hz}\right), 1.46(36 \mathrm{H}, \mathrm{s}) ;{ }^{13} \mathrm{C}$ NMR (400 MHz, $\left.\mathrm{CDCl}_{3}, \mathrm{ppm}\right) \delta 142.53,140.23,139.06,130.53$,
125.98, 124.14, 123.53, 123.11, 119.44, 116.17, 111.84, 109.11, 34.72, 32.04; MS (ES) $m / z, 722\left(\mathrm{M}+\mathrm{H}^{+}\right)$.

E. 4,7-Bis $\left(3,6,3^{\prime \prime}, 6^{\prime \prime}\right.$-tetrakis-tert-butyl[9,3'; $\left.6^{\prime}, 9^{\prime \prime}\right]$ tercarbazol-9'yl)-[1,10]-phenanthroline (L2). The unprotected trimer (640 mg, 0.9 $\mathrm{mmol})$ and $\mathrm{NaH}(85 \mathrm{mg}, 3.5 \mathrm{mmol})$ in THF was stirred for $30 \mathrm{~min}$. 4,7-Dichlorophenanthroline (100 $\mathrm{mg}, 0.4 \mathrm{mmol}$ ) was added to the reaction mixture, and it was allowed to reflux overnight. THF was evaporated, and the residue was dissolved in dichloromethane. After washing with water, drying over $\mathrm{MgSO}_{4}$, and evaporating the solvents, we purified the crude product by column chromatography over silica using a mixture of dichloromethane/methanol (20:1, v/v) as eluent. After evaporation to dryness, an off-white solid was obtained $(250 \mathrm{mg}$, yield $=38 \%) \cdot \mathrm{Mp}=332-335{ }^{\circ} \mathrm{C} ;{ }^{1} \mathrm{H}$ NMR $\left(300 \mathrm{MHz}, \mathrm{CDCl}_{3}, \mathrm{ppm}\right) \delta$ $9.64\left(2 \mathrm{H}, \mathrm{d},{ }^{3} J=4.8 \mathrm{~Hz}\right), 8.29\left(4 \mathrm{H}, \mathrm{d},{ }^{4} J=1.8 \mathrm{~Hz}\right), 8.14(8 \mathrm{H}, \mathrm{d}$, $\left.{ }^{4} J=1.8 \mathrm{~Hz}\right), 8.08\left(2 \mathrm{H}, \mathrm{d},{ }^{3} J=4.8 \mathrm{~Hz}\right), 7.84(2 \mathrm{H}, \mathrm{s}), 7.59(4 \mathrm{H}, \mathrm{dd}$, $\left.{ }^{3} J=8.4 \mathrm{~Hz},{ }^{4} J=1.8 \mathrm{~Hz}\right), 7.43\left(8 \mathrm{H}, \mathrm{dd},{ }^{3} \mathrm{~J}=8.4 \mathrm{~Hz},{ }^{4} J=1.8 \mathrm{~Hz}\right)$, $7.35\left(4 \mathrm{H}, \mathrm{d},{ }^{3} J=8.4 \mathrm{~Hz}\right), 7.32\left(8 \mathrm{H}, \mathrm{d},{ }^{3} J=8.4 \mathrm{~Hz}\right), 1.44(72 \mathrm{H}, \mathrm{s})$; ${ }^{13} \mathrm{C}$ NMR $\left(400 \mathrm{MHz}, \mathrm{CDCl}_{3}\right.$, ppm) $\delta 151.9,148.9,142.9,142.8,140.6$, 140.0, 132.0, 128.2, 126.6, 126.4, 124.7, 123.6, 123.2, 119.6, 116.3, 111.3, 109.0, 34.7, 32.0; MS(ES) $\mathrm{m} / z .1620$.

F. $\left[(\text { bpy })_{2} \mathbf{R u}(\mathrm{L1})\right]\left(\mathrm{PF}_{6}\right)_{2}(1)$ and $\left[(\mathrm{bpy})_{2} \mathrm{Ru}(\mathrm{L} 2)\right]\left(\mathrm{PF}_{6}\right)_{2}$ (2). Ru(bpy) ${ }_{2} \mathrm{Cl}_{2} \cdot 2 \mathrm{H}_{2} \mathrm{O}(40 \mathrm{mg})$ and $\mathbf{~} \mathbf{1} / \mathbf{L} \mathbf{2}$ (1.1 equiv) were added to wet DMF $(6 \mathrm{~mL})$ and heated at $120^{\circ} \mathrm{C}$ for $48 \mathrm{~h}$. After the mixture was cooled to ambient temperature, an excess of solid $\mathrm{NH}_{4} \mathrm{PF}_{6}$ was added. The reaction mixture was purified by passing on a column of alumina, prepared with toluene/acetonitrile $(4: 1, \mathrm{v} / \mathrm{v})$. The product was eluted using neat acetonitrile, after gradually biasing the solvent mixture. After concentration, the samples were further purified on a Sephadex G-10 column. The product was then recrystallized from toluene/acetonitrile, filtered-off, and washed repeatedly with water and diethyl ether before drying under vacuum. Compounds $\mathbf{1}$ and $\mathbf{2}$ were obtained as orange powders $(\mathbf{1}, 90 \mathrm{mg}$, yield $=82 \% ; \mathbf{2}, 131 \mathrm{mg}$, yield $=75 \%) . \mathbf{1}:{ }^{1} \mathrm{H}$ NMR (300 MHz, $\left.\mathrm{CD}_{3} \mathrm{CN}, \mathrm{ppm}\right) \delta 8.63-8.57(4 \mathrm{H}, \mathrm{m}), 8.33-8.28(6$ $\mathrm{H}, \mathrm{m}), 8.18-8.10(4 \mathrm{H}, \mathrm{m}), 7.97-7.90$ (6 H, m), 7.75 (2 H, s), 7.59$7.43(8 \mathrm{H}, \mathrm{m}), 7.37(2 \mathrm{H}, \mathrm{d}, J=9 \mathrm{~Hz}), 7.07(2 \mathrm{H}, \mathrm{d}, J=8.7 \mathrm{~Hz}), 1.46$ $(18 \mathrm{H}, \mathrm{s}), 1.43(18 \mathrm{H}, \mathrm{s})$; MS (ES) m/z, 1293 (10\%, M-PF $), 574(100 \%$, M-2PF $)$; MALDI-TOF $1293\left(\mathrm{M}-\mathrm{PF}_{6}\right), 1148\left(\mathrm{M}-2 \mathrm{PF}_{6}\right) .2$ : ${ }^{1} \mathrm{H}$ NMR (300 MHz, $\left.\mathrm{CD}_{3} \mathrm{CN}, \mathrm{ppm}\right) \delta 8.69-8.59(4 \mathrm{H}, \mathrm{m}), 8.49(6 \mathrm{H}, \mathrm{d}, J=6$ $\mathrm{Hz}), 8.26(8 \mathrm{H}, \mathrm{d}, J=4.5 \mathrm{~Hz}), 8.22-8.11(6 \mathrm{H}, \mathrm{m}), 8.05(4 \mathrm{H}, \mathrm{s})$, $7.97(2 \mathrm{H}, \mathrm{d}, J=5 \mathrm{~Hz}), 7.81(2 \mathrm{H}, \mathrm{d}, J=9 \mathrm{~Hz}), 7.74(2 \mathrm{H}, \mathrm{d}, J=9$ $\mathrm{Hz}), 7.66-7.41(18 \mathrm{H}, \mathrm{m}), 7.36-7.26(6 \mathrm{H}, \mathrm{m}), 1.43$ (36 H, s), 1.41 (36 H, s); MS (ES) $2177 \mathrm{~m} / \mathrm{z}\left(8 \%, \mathrm{M}-\mathrm{PF}_{6}\right), 1017$ (100\%, M-2PF $)$; MALDI-TOF $2178\left(\mathrm{M}-\mathrm{PF}_{6}\right), 2033\left(\mathrm{M}-2 \mathrm{PF}_{6}\right)$.

G. $\left[\mathbf{R u}\left(\mathbf{L 1}_{3}\right)\right]\left(\mathbf{P F}_{\mathbf{6}}\right)_{\mathbf{2}} \mathbf{( 3 )} \cdot \mathrm{RuCl}_{3} \cdot 3 \mathrm{H}_{2} \mathrm{O}(10 \mathrm{mg})$ and $\mathbf{~ L 1}(90 \mathrm{mg}, 3.2$ equiv) in wet DMF $(10 \mathrm{~mL})$ were heated for 5 days at $120{ }^{\circ} \mathrm{C}$. Methanol/water $(5 \mathrm{~mL}, 3: 1, \mathrm{v} / \mathrm{v})$ was added, and the mixture was refluxed for 2 more days. After the mixture was cooled and the addition of excess solid $\mathrm{NH}_{4} \mathrm{PF}_{6}$, solvents were removed under reduced pressure. Acetonitrile was added to the residue which was filtered and washed repeatedly with acetonitrile. The filtrate was concentrated and purified on a column of neutral alumina, prepared with toluene/acetonitrile (4: $1, \mathrm{v} / \mathrm{v})$. The product was eluted using acetonitrile, after gradually biasing the solvent mixture. Further purification was achieved via chromatography with a column of sephadex, to yield the product as an orange solid $(67 \mathrm{mg}$, yield $=68 \%) .{ }^{1} \mathrm{H}$ NMR $\left(300 \mathrm{MHz}, \mathrm{CD}_{3} \mathrm{CN}, \mathrm{ppm}\right) \delta$ $8.68(6 \mathrm{H}, \mathrm{d}, J=4.2 \mathrm{~Hz}), 8.25(12 \mathrm{H}, \mathrm{s}), 8.01(6 \mathrm{H}, \mathrm{d}, J=4.2 \mathrm{~Hz})$, $7.75(6 \mathrm{H}, \mathrm{s}), 7.49-7.35(18 \mathrm{H}, \mathrm{m}), 7.06(6 \mathrm{H}, \mathrm{d}, 8.7 \mathrm{~Hz}), 1.35(54 \mathrm{H}$, s), $1.33(54 \mathrm{H}, \mathrm{s})$; MALDI-TOF $2306\left(\mathrm{M}-2 \mathrm{PF}_{6}\right)$.

Acknowledgment. We thank COST (Action 11, program on Supramolecular Chemistry), the MIUR, CNR (Agenzia 2000), TMR research network program (Contract No. ERBFMRX-98CT-0226 on "Nanometer size metal complexes") for financial support. W.D. thanks the K. U. Leuven, the F.W.O.-Vlaanderen, and the Ministerie voor Wetenschapsbeleid for their continuing 
support. A.H. thanks the K. U. Leuven for a PhD fellowship. F.L. thanks the Marie Curie Individual Fellowship program.

Supporting Information Available: Absorption and emission titration curves for $\mathbf{L} \mathbf{1}$ and $\mathbf{L} \mathbf{2}$ on trifluoroacetic acid addition, table collecting emission maxima of $\mathbf{L} \mathbf{1}$ and $\mathbf{L} \mathbf{2}$ in different solvents, and cyclic and pulse voltammetry curves of most of compounds studied. This material is available free of charge via the Internet at http://pubs.acs.org.

JA021373Y 